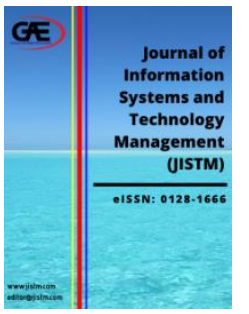

\author{
JOURNAL OF INFORMATION \\ SYSTEM AND TECHNOLOGY \\ MANAGEMENT (JISTM) \\ WWW.jistm.com
}

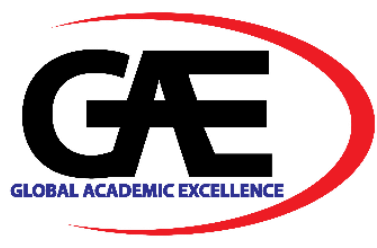

\title{
SMARTPHONE APPLICATION DEVELOPMENT FOR FOOD BLOGGERS: A CASE STUDY IN BANGKOK
}

\author{
Pittaya Kanithabutra $^{1}$, Patthama Hengtragul ${ }^{2}$, Thongchai Surinwarangkoon ${ }^{3 *}$, Vinh Truong Hoang ${ }^{4}$ \\ Faculty of Management Science, Suan Sunandha Rajabhat University, Bangkok, Thailand \\ Faculty of Management Science, Suan Sunandha Rajabhat University, Bangkok, Thailand \\ Faculty of Management Science, Suan Sunandha Rajabhat University, Bangkok, Thailand \\ Email: thongchai.su@ssru.ac.th \\ 4 Faculty of Information Technology, Ho Chi Minh City Open University, Ho Chi Minh, Vietnam \\ * Corresponding Author
}

\section{Article Info:}

\section{Article history:}

Received date: 13.07 .2020

Revised date: 10.08 .2020

Accepted date: 30.09 .2020

Published date: 01.12.2020

\section{To cite this document:}

Kanithabutra, P., Hengtragul, P., Surinwarangkoon, T., \& Hoang, V. T. (2020). Smartphone Application Development for Food Bloggers: A Case Study in Bangkok. Journal of Information System and Technology Management, 5 (19), 77-92.

DOI: $10.35631 /$ JISTM.519007.

This work is licensed under CC BY 4.0 (c) 2
Abstract:

The objective of this research was to 1) study and develop a smartphone application for food bloggers, and 2) evaluate the result of using the application regarding the benefits of usage. This is mixed-method research and development. The application development processes composed of the study of user requirements, application design, application development, application testing, improvement, and evaluation. In the study of the user requirement process, data were collected from research samples by questionnaires. 400 research samples were selected from Thai people in the Bangkok area by a simple random sampling method. Data were analyzed in terms of frequency, percentage, mean, and standard deviation. Moreover, researchers also conducted interviews in order to collect qualitative data from 2 food bloggers in Bangkok about the requirements and relevant information about food blog application. After that, the smartphone application for food bloggers was designed, developed, tested, improved, and evaluated. Research results were as the followings. In terms of application users, the relevant activities composed of user registration, food contents uploading and presentations, comments, and evaluations. The application provided food details information, such as food menus, ingredients, cooking process, etc. in terms of texts, pictures, and videos. Food information was classified in terms of food types, nature of food culture by countries, and popular food ranking. Comment page show details about user comments with comments about posts. The application focused on colorful, beautiful, pleasant to use, which was appropriate for those who like to present food and let others know about restaurants and food in various stores. The developed smartphone application provided a social media channel. Users can register and log in through the application in order to submit their work by posting a message, pictures, and details about food information 


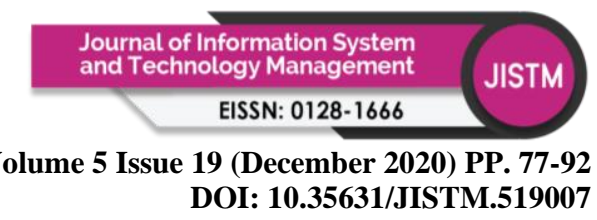

\begin{abstract}
that they want to offer. Bloggers can edit posts made by themselves easily. Visitors can follow food bloggers which they are interested in. However, the researcher had suggestions as follows: 1) the food blog owner should provide more foreign languages, such as English, Chinese, Japanese for users in order to promote Thai food tourism, 2) some famous food bloggers should be invited to write some interesting content in order to promote application marketing, 3)interesting cooking lesson should be provided to visitors, 4) food contents must be active regularly, 5) the application sponsors must be arranged as well, and 6) food block owner have to set good rules and regulations for food blockers and visitors clearly.
\end{abstract}

Keywords:

Smartphone, Application Development, Food Bloggers

\title{
Introduction
}

Nowadays, digital technology has developed continuously, and rapidly. Information technology becomes an important part for everyday life. People use various digital technology devices for convenience, such as smartphone, tablets, notebooks, and personnel computers. According to the survey of Thai Internet Barometer 2016 user behavior, it revealed that 85 percentages of Thais visited websites every day, 69 percentages of Thais are moving forward to the digital users. More than 70 percentages of Thais accessed the internet via mobile devices and 58 percentages of Thais used internet to do many activities at the same time. The smartphone usages grow increasingly. Many leading smartphone companies turn their attention to smartphone application development. It is believed that there will be a significant download growth rate for applications (Online Seminar, 2014). The most people use their smartphones, resulting in the development of many different types of applications.

Nowadays, the most people are interested in eating quite a lot which it can be seen from YouTube. There were a lot of content about eating in different restaurants, making self-cooking clips and eating shows, cooking lessons for viewers which we can see from many views from YouTube (Phichit, 2011).

Today, food blogger careers are becoming very popular. They often use online media to present information such as Facebook, YouTube, Instagram, etc. in order to present interesting restaurants, review the atmosphere of the restaurant, and review the dishes of that restaurant which makes viewers interested and follow their works (Online Semina,2014). However, there is no special direct application for food content in Thailand. There is no central application for viewers to easily visit. When looking at food bloggers which they are interested, they have to open the page or other channels. Users may search for their interests, but it is a waste of time. There are no immediate options, without provided classifications. Currently, there are no application providers for direct integration of food bloggers (Kannikar, 2019).

Therefore, the researcher has realized the importance of using smartphone technology to fulfill this study and developed an application, namely "Pinto", or food carrier, which provided and classified various types of food information, such as food of each country, raw materials, ingredients, etc. The food bloggers can present their contents in terms of texts, pictures, and videos easily and user can exchange their ideas about cooking (Manoch, 2019). 


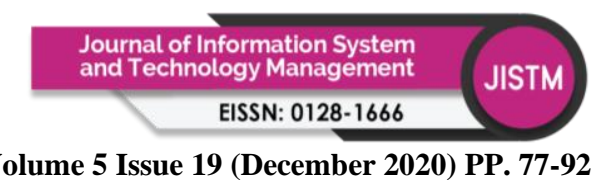

Volume 5 Issue 19 (December 2020) PP. 77-92

DOI: 10.35631/JISTM.519007

\section{Literature Review}

The concepts, principles, and theories related to smartphone application development for food bloggers are as follows:

\section{Concept of Consumer Behavior}

Consumer behavior refers to the study of units of purchase and exchange processes related to acquisition, consumption and limitations on products, services, experiences and ideas (Mowen and Michael, 1998). Consumer behavior refers to the behavior in which a consumer conducts searches in connection with a purchase, using pay estimates in products and services, expecting to meet his needs (Schiffman and Leslie, 1994). Consumer behavior is direct reactions which relates to the acquisition and use of economic goods and services. It includes the processes of decision-making that precede and dictate those reactions.

Satisfaction is the feeling that customers have about products and services and is a factor that influences their intention to return to the service again in the future. Therefore, satisfaction refers to the happiness of the consumer when it comes to the expected response to their needs (Wolman, 1973), as well as the perception of a positive experience that includes fun, comfort, and enjoyment whenever the service meets the needs of consumers (Chatura, Harvir, and Gordon, 2008). Satisfaction is enough to increase business chances in order to increase the liking of a brand and it makes consumers think of that brand (Westbrook and Oliver, 1981).

\section{Concepts of Decision Making in Cognitive Processes}

Buying decisions are the cognitive processes of a consumer in deciding to purchase a different product or service. In which consumer purchasing behavior cannot occur immediately, there is a need for a hierarchical thinking process (Wut, 2012). The previous purchase decision will influence the next purchase decision as well (Pavinee, 2011). The consumer decision-making process is a step-by-step process of expressing feelings and behaviors of customers. Consumer decision-making process consists of 5 steps as follows: awareness of the problem, seeking information, evaluation of options, buying decision, and behavior after the purchase, respectively.

\section{Concepts of Mass Media Influencing on Food Consumption}

In choosing to buy products or services of consumers, there are factors that determine the behavior. Consumer judgments composed of internal factors and external factors. Internal factors that influence consumer behavioral decisions are as follows: needs, wants, and desires, motive, personality, attitude, perception, and learning. 1) Needs, wants, and desires are used for considering the purchase of goods or services that are necessary for living, 2) Motive is the problem that reaches the critical point causing consumers to feel uncomfortable. Motivation is therefore a desire and it can motivate people to find ways to meet their satisfaction with motivation based on necessity. Therefore, marketers have a duty to encourage consumers need to buy products or services until it enters a crisis that causes consumers to be extremely uneasy and allowing consumers to find ways to meet those needs. 3) Personality is the overall trait of the individual which has different effects on determining on the personality of the individual as well. 4) Attitude is an assessment of the consumer's satisfaction with something. Attitude is the behavior of consumers. There are 3 aspects of attitude, which are knowledge, feelings, and trends. Marketers try to change these 3 customer's habits. For consumers who have a good view on the products or services, the company try to keep it, but if any consumer has a bad 


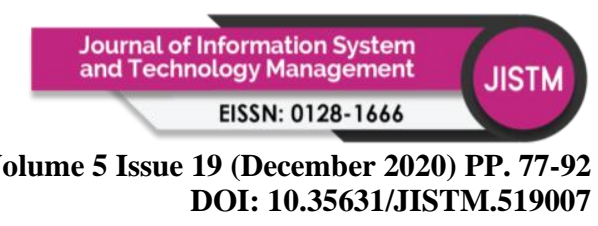

attitude towards the company's products or services, the company will try to change the attitude of that person to turn to like the company's products or services in the end. 5) Perception is the person choosing to receive and interpret the information in order to define meaningful images in marketing. Perception is like a channel for marketers to create a good image for the brand or create a good image for management until the consumer has a good awareness for the brand or create a good image of the service. Thus, the opportunity for consumers to buy products or services of the company will be easier. 7) Learning is a change in behavior of a person which caused by personal experience. Learning is an experience that people have accumulated. Therefore, marketers have the duty to put experience and learning about the right brand or service to consumers (Padthama, 2007).

External factors that affect consumer decision-making behavior are as follows: economy, family, society, and culture. Economy determines the purchasing power of the consumer or the economic opportunity of an individual, namely the income of the person which has purchasing power and attitude about payment. Consumers who have high demand, but the product or service is too expensive, they cannot buy. The family causes the response to the demand for products or services that meet the needs of consumer, which was influenced by members of the family. Society or social group effects the same way of living for people. The same attitude, the appearance of consumers will be in the same society, such as sports, sport club and heritage club. Consumers who use these services, will be in the same group. Culture is a group of basic values, perceptions, needs, and behaviors which learned from being a member of society in the family. Culture is a form or way of life that most people accept which consists of values and expressions. Value of using objects or things in each culture group are unique and different, especially in a large and complex society. This characteristic is due to geographical or local basis in different lifestyles.

Advertising and mass media are considered a popular channel because it is easily accessible. It helps to relieve stress and provide enjoyment. Therefore, advertising and mass media influence consumer behavior, resulting in imitations of behaviors or values from famous people.

\section{Concepts and Theories of Social Media}

Nowadays, society has changed a lot since the online media has rapidly progressed. Today's society does not need to communicate face to face but people can communicate more easily anytime and anywhere by using online media as the main tool.

Humans are societies that need to communicate with each other. In ancient times, humans communicated information in uncomplicated ways such as oral talk, horse and pigeon communicate. After that, data communication was changed to mail, telegraph, telephone and radio. When entering an age where computer networks and the internet are involved human data communication has changed into more electronic-related media such as Internet Relay Chat (IRC) programs, electronic mail or e-mail, and web-board. At present, humans began to communicate with each other on a daily basis as well (Phichit, 2011).

Social media is the media that the messenger shares in various forms to the recipients via the online network. The messenger and the receiver or recipients can interact themselves. Social media can be divided into various categories. The most commonly used social media are blogging, tweets and Micro-blogging (Twitter and Microblogging), social networking and media sharing. 


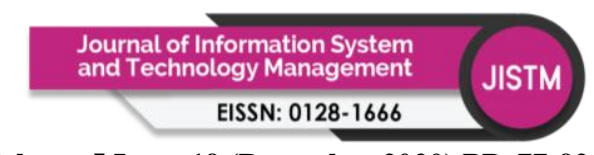

Volume 5 Issue 19 (December 2020) PP. 77-92 DOI: 10.35631/JISTM.519007

Blog comes from Web and Log. Blog is a type of content management system which it facilitates blog authors to publish and share their own articles. By articles posted on blogs, it is a personal comment of a blog author. The highlight of the blog is the friendly communication between the author and the readers of the blog through comment. Blogger (www.blogger.com) and WordPress (www.wordpress.com) are two websites that people like to create their own blogs.

There were 4 types of bloggers: independent bloggers, business bloggers, enterprise bloggers, and professional bloggers. Independent bloggers write their own blogs by restricting one's own blog to be a personal blog for writing personal stories or personal thoughts without presenting their own blog for other purposes, aside from watching for entertainment and fun among friends. Business bloggers often write blog content for business purposes which is the introduction of their products or services. They use blogs as a means of marketing communication for their business. Enterprise bloggers use blogs for internal communication, whether within the organization or company, such as for communication within a football team or various clubs. Professional bloggers will only write blogs by earning money from a blog for sustenance. Some bloggers are paid in salaries for blogs writing only. Some people write their own blogs by receiving various advertising fees from sponsors. This group may be a company that specifically writes blogs. Professional bloggers will write specific topics that are interesting to many people online. Some people earn income from being a presenter for various products (Sahassa, 2008).

\section{Mobile Application Usage}

The trend of using smartphones has increased exponentially. This is the result of the development of mobile applications and phone technology from manufacturers, especially the development of mobile applications of companies competing. Application development is divided into development of system applications or operating system and software applications that respond to works on devices with the growing and more powerful applications. Mobile users are more likely to use programs to meet their daily activities, including financial transactions, internet connection and browsing, watching movies, listening to music or even playing games, both online and offline (Suchada, 2011). Benefits of mobile application usages for business groups, both large and small, were as followings: 1) having tools to promote their own businesses, making them more known in society, 2) reduce the cost of producing media for advertising and public relations, 3) increasing good business image, strengths and selling points, resulting in more business sales, 4) supporting better customer service, and 5) reducing work procedures, making it convenient to contact various business operations. Benefits of mobile application usage for consumers were as followings: 1) reducing the procedure and time saving in dealing with various transactions such as money transfers, 2) providing a variety of options, which quality and price can be compared without exploring the market, and 3) saving money in choosing various services (Thongchai and Chinoros, 2020).

\section{Technology for Mobile Application Development}

Mobile applications are divided into 3 types: native application, hybrid application, and web application. Native application was developed by Library (SDK) or SDK which they are tools for developing applications of that particular operating system (OS) mobile phone. For example, Android uses the Android SDK, iOS uses Objective C, Windows Phone uses C \#, etc. Hybrid application was developed with the aim of being able to run on all operating 


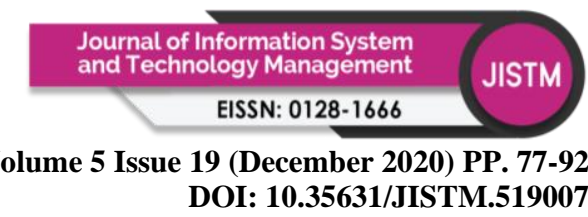

systems using the framework or command set. Web application is an application that has been written as a browser for using various web pages that are customized to display only the necessary parts. In order to reduce the processing resources of the device, smartphone or tablet, resulting in faster website loading. In addition, users can also use the internet and intranets at a low speed.

Android is an operating system for portable devices such as mobile phone tablet computers, netbooks. Android was developed by Android Incorporation. After that, Google bought the Android Company in August 2005 and further developed the Android operating system, and Google allowed developers to edit Java code and control the device via the Java libraries. In 2007, there was a collaboration of leading companies regarding manufacture hardware, software, including telecommunication companies such as Motorola, Samsung, HTC, Intel, Marvel, NVidia, etc. under the Open Hands Alliance (OHA) partnership to develop open standards for copyright mobile devices. This Android code will be used in the open source software of Android architecture.

\section{Concepts and Theories for Analyzing and Designing Applications}

Good user interface design included visibility, development and acceptance. Visibility is clear that indicates the uniqueness of the application by considering usage and having a clear concept. Development must take into account the ability to customize and the limitations of the platform, such as support for rapid prototyping, data warehousing, and a set of tools to support further development. Acceptance means accepting the patent agreement and organization policy, not in conflict with regulations.

Application design principles composed of communication, economization, and organization. Communication is a coherence between user and usage functions such as various interactive usage behaviors. Economization minimize the number of procedures for user interface operations, but it must be as comprehensive as possible. Organization means the user interface must have a clear structure of use and concepts.

There are 3 basic tools that can help to increase application efficiency: canvas, sidebar, and toolbar. Canvas can show what users are currently running which application designer have to know the needs and behavior of users. Moreover, designing must be the answer to the problem and easy to use. Sidebar helps to access special parts or the application's hidden menu. Toolbar allows users to select or change options or change the menu to use the application. These basic tools are already familiar for users and it helps to make the design easier as well.

Choosing a good color will help users to remember better than just using black and white as well as to increase efficiency and attract users as well. In addition, the benefits of using color also include helps to visualize and understand better, emphasize the importance of data, help the graphic design to be more natural, reduce interpretation errors, and increase visibility for better images. Developer have to choose a font that is easy to read in all formats. The font display is quite difficult to read on small screens. The best way is to choose simple fonts such as serif and sans serif. If the device does not support the font, it will be replaced and may display in strange characters. Application design, which use different languages, must consider the letter stretching and it may use up to 50 percentages more space. It is necessary to combine many features, but it may cause the application to lag. The solution is to use the dropdown menu or tap in order to help for display of tools and useful information at the same time, 


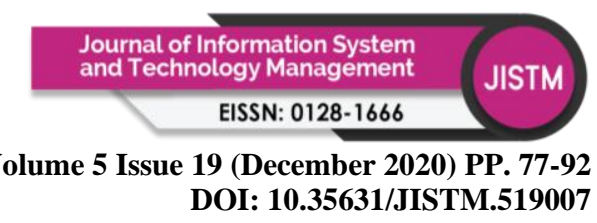

including making it as simple and easy to use as possible. Generally, users will not only choose to use the application that looks easy to use but also consider the function of usage.

\section{Relevant Researches}

Tarika (2011) conducted a study on factors affecting the use of smartphone applications of people in Bangkok. The purpose of the research was to study the characteristics of demographic data from samples in Bangkok that use the application, factors affecting the application selection, and relationship between technology development of mobile phones and the application selection for using on smartphone. The samples were selected from people in Bangkok. The results showed that the most of samples were between 20-29 years old, graduated bachelor degree, received income 10,000-15,000 Baht per month. They used about 1-5 applications per day and used social network on a regular basis. Most of the samples used social network in order to chat with friends and used applications for entertainments.

Suchada (2011) studied the trend of mobile application usage and found that the trend of mobile device usage, such as smart phones, has increased dramatically in the past few years which was a result of the development of mobile applications and the technology of the phone from the phone manufacturers. In particularly, the development of mobile applications for companies that compete for the number one in the mobile application markets, in which application development is divided into system application development. (Operation System) and application software which responds to usage on the devices. Increased and more efficient applications allow mobile device users tend to use various applications in order to meet daily activities, such as conducting financial transactions, connecting and searching information on the internet, watching movies, listening to music or even playing games in terms of both online and offline. The rapid growth of mobile device usage has made many leading mobile phone companies turn their attention to mobile phone application development. It is believed that there will be a significant download growth rate for applications.

Kannika (2013) aimed that mobile phones or smartphones can connect to the internet in order to meet the needs of news and information. Android operating system is a smartphone-based operating system with a large number of users. Developing applications on this operating system will make it accessible to a large number of users. National parks in Thailand are becoming increasingly popular natural attractions. Many facilities were provided in various parks. Mobile application projects for national park tourism in Thailand have been prepared to facilitate tourists who are interested in being able to search the park information according to their interests. This project stored the national park database on the server and develop applications in order to install on mobile phone for information searching. The searching result will be retrieved from the server to display on the mobile screen. From evaluating the use of the program from a sample of 30 users, it was found that the satisfaction level of program users was very good. The developed application had an easy-to-use interface that can display park information based on searching results correctly. Therefore, this application can be used as a channel to publicize national parks in Thailand.

Purim (2016) developed an application for finding restaurants using Android system via GPS and studied the satisfaction of website users, managing restaurant information and applications for finding a restaurant. The samples were 20 general users who are interested in the Android operating system in Buri Ram province, Thailand. The research tool was the satisfaction evaluation form for using the restaurant search system by using Android via GPS. Statistics for 


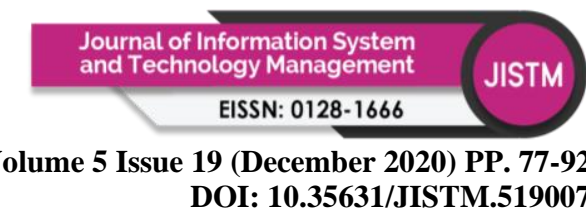

data analysis were mean and standard deviation. The results of the research were as follows: 1) the restaurant search system using Android system via GPS composed of website and application section, and 2) users were satisfied with the use of the restaurant search system using Android via GPS. The overall user satisfaction was at a high level.

Panthita and Tranakjit (2017) conducted a study on the exposure and behavior of using Wongnai applications of consumers who used Wongnai application. The results of the study can be summarized as follows: the most of samples, who received application marketing communications from Wongnai, were female, aged 20-25 years old, following by aged 26-30 years old. The most of them received Bachelor's Degree, worked in private companies, and had average income 20,001-25,000 Baht per month. Almost of them were urban people and prefer to eat out rather than cook themselves. According to Khun Yod Chinsupakul, he has set the target group of Wong Nai Media Company Limited as a group of workers and teenagers as well as want to create convenience for the urban people in the area of restaurants regarding market exposure of Wongnai applications of consumers using Wongnai application. The most of samples were open to marketing communications of Wongnai application via Facebook, following by www.wongnai.com, Line official account: Wongnai, Instagram: Wongnai and Twitter: Wongnai, respectively. The Office of Electronic Transactions Development (Public Organization) (ETD) or ETDA (Etda), Ministry of Technology Information and Communication, stated that the most of Thais use Facebook, followed by LINE, Instagram, and Twitter, respectively (Brandinside, 2016).

Bunyaporn (2017) conducted a study on restaurant reviews via social media and the restaurant selection decisions for eating out of consumers in Bangkok. It can be founded that restaurant reviews via social media effected the decision to choose restaurants for eating out. Nattha (2010) revealed that communication through social media affected the perception of customers as follows: 1) the website must be credible, 2) content must be in line with customer needs, and 3) communication channel need to be fast in the network system.

Isarawalee (2017) conducted a study on the decision to use the LINE MAN application service in Bangkok. It was found that the most important motivation that affects the intention to use LINE MAN application was getting advice from other people directly, and next was sales promotion or promotion activities.

\section{Methodology}

\section{Research Objectives}

The objectives of this research were to: 1) study and develop smartphone application for food bloggers, and 2) evaluate the result of using the application regarding the benefits of usage.

\section{Research Scope}

This research starts from January 2020 to April 2020. The application development processes composed of the study of user requirements, application design, application development, application testing, improvement, and evaluation. In terms of users, the study composed of user registration, food contents uploading and presentations, comments and evaluations (Designil, 2019). Scope of application composed of user registration, content insertion and uploading in terms of text image and video, review and application evaluation. Scope of application 


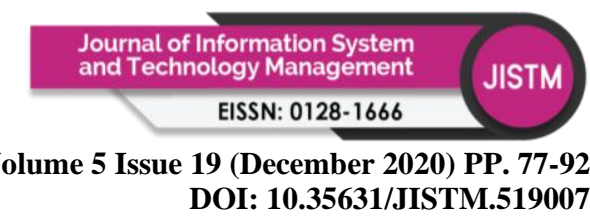

developer composed of user authentication, application problem solving, comment and evaluation checking which users had assessed, application development and improvement.

\section{Research Methodology}

This is a mixed-method research and development. In the study of user requirement process, data were collected from research samples by questionnaires in order to study sample's demographic background, social media usage, food blog visit behaviors, demands of smartphone application development for food blogs, etc. 400 research samples were selected from Thai people in Bangkok area by simple random sampling method. Sample size was determined by using Yamane's formula at 0.95 confident level (Yamane, 1967). Then, quantitative data were analyzed in terms of frequency, percentage, mean, and standard deviation. Moreover, researchers also conducted interviewing in order to collect qualitative data from 2 food bloggers in Bangkok about the requirements and relevant information about food blog application. After that, the smartphone application for food bloggers were designed, developed, tested, improved, and evaluated.

\section{Findings and Discussion}

\section{Demographic Background of Samples and Behaviors of Food Blog Usage}

Almost of research samples were female, 66.7 percentages, and remain samples were male, 33.3 percentages. The most of them were between $21-25$ years old, 43.3 percentages, following by aged between 26-30 years old, 26.7 percentages, aged 20 years old and below, 16.7 percentages, aged between 31-35 years old, 10.0 percentages, aged over 35 years old, 3.3 percentages, respectively. The most of samples were students, 50 percentages, following by having own business, 30 percentages, government officials and state enterprise, 13.3 percentages, and employees in business organizations, 6.7 percentages, respectively. Sample group, who have salary between 5,000-10,000 Baht per month, was at 26.7 percentages while sample group, who have salary below 5,000 Baht per month, was at 26.7 percentages, following by salary more than 25,000 Baht per month, 16.6 percentages, salary between 10,001-15,000 Baht per month, 10.0 percentages, salary between 15,001-20,000 Baht per month, 10.0 percentages, and salary between 20,001-25,000 Baht per month, 10.0 percentages, respectively.

The most of samples used social media for restaurant information searching for their eating between 3-5 times per week, 55.6 percentages, following by less than 3 times per week, 27.8 percentages, between 6-8 times per week, 11.0 percentages, and more than 8 times per week, 5.6 percentages, respectively. The most favorite type of restaurants for their visits in food blogs were a la carte Thai restaurants, 44.4 percentages, following by papaya salad restaurants, 33.3 percentages, noodle restaurants, 11.1 percentages and Japanese restaurants, 11.1 percentages, respectively.

Table 1: Demands of Smartphone Application Development for Food Bloggers

\begin{tabular}{cccc}
\hline Topic & Mean & Standard Deviation & Level \\
\hline Food blogs usage & 3.93 & 1.081 & High \\
Ease of use & 3.90 & 0.885 & High \\
Subscription system & 3.90 & 1.029 & High \\
Providing food discount information & 4.10 & 0.759 & High \\
Food menus display & 3.87 & 0.860 & High \\
\hline
\end{tabular}


Volume 5 Issue 19 (December 2020) PP. 77-92 DOI: 10.35631/JISTM.519007

\begin{tabular}{cccc}
\hline Price display with restaurant information & 3.97 & 0.964 & High \\
Map display & 3.83 & 0.874 & High \\
Rating system & 3.50 & 0.974 & High \\
Comment system & 4.00 & 0.830 & High \\
Update information & 4.07 & 0.907 & High \\
Total & $\mathbf{3 . 9 0 7}$ & $\mathbf{0 . 9 1 6}$ & High \\
\hline
\end{tabular}

Table 1 showed demands of smartphone application development for food bloggers. It was found that the needs of the users of smartphone application development for food bloggers had a total mean of 3.907, standard deviation of 0.916 , which was at a high level. The topic that users are most likely to want was the application to recommend restaurants with food discount information, which the mean was 4.10, standard deviation of 0.759 . The second-high level topic was requiring the application to be consistently update, with the mean of 4.07, standard deviation of 0.907 . The third high level topic was requiring the application to provide comment system, with the mean of 4.00 , standard deviation of 0.830 .

\section{Demand for Smartphone Application Development for Food Bloggers}

From literature review and data analysis results, it was found that user's requirements for smartphone application development for food bloggers were as follows: 1) Application users wish to have a subscription system in order to access the application by non-member users must register. Once registering, you will be able to log in to use the application to recommend food and restaurants in Bangkok. 2) The users of the application want to view food and restaurant information such as food menus and restaurant atmosphere. 3) Users of the application wish to have their opinions expressed by members which members can be able to comment on food and restaurants. Users can also view comments which were made by other users. 4) Users of the application wish to have a rating system. This is the rating of foods within the application as an alternative to the decision of the restaurant. 5) Users of the application want the restaurant's location to be displayed in order to know the location of the restaurant and how to get to that restaurant. 6) The users of the application wish to have a discount section that can be applied to the restaurant lists in the application in order to get discount from the restaurant and it is also what attracts customers to use the service. 7) The users want the blogger to provide updated information such as location of some restaurants that have changed, menu items for each food, menu of the restaurant, and new restaurant information.

\section{Result of Smartphone Application Development}

This research developed a smartphone application development for food bloggers, namely Pinto, or food carriers. The application user, who is able to use the application, must be a member only. The system analysis and design process for smartphone application development for food bloggers composed of 5 operation processes: site map, context diagram, data flow diagram, entity-relationship diagram and data dictionary. Site map of Pinto application was shown in figure 1. 


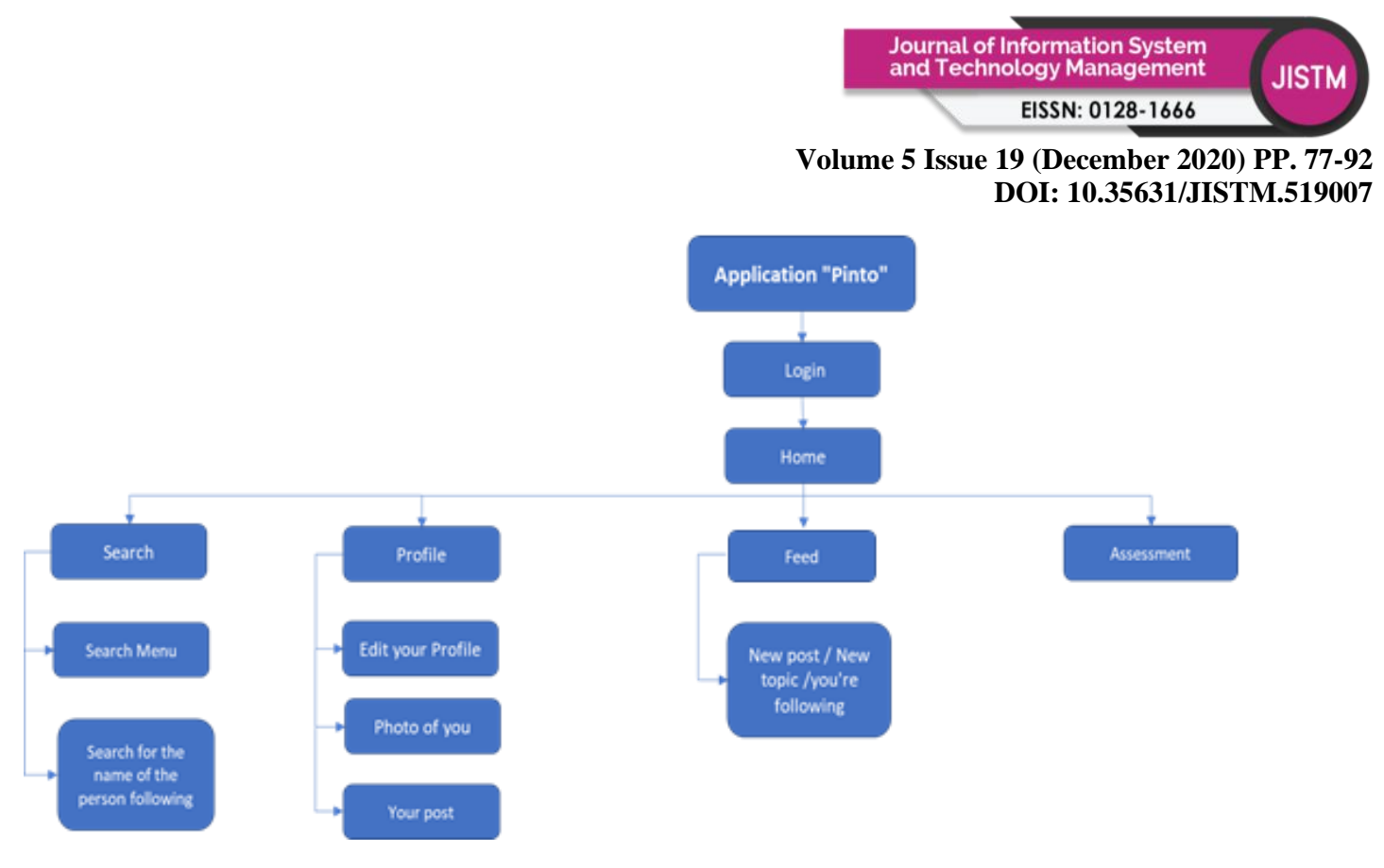

Figure :. Site Map of Pinto Application

The main page showed details about the application principles, questionnaire for users to suggest to the developers, and contact information. The main page was illustrated in figure 2 .

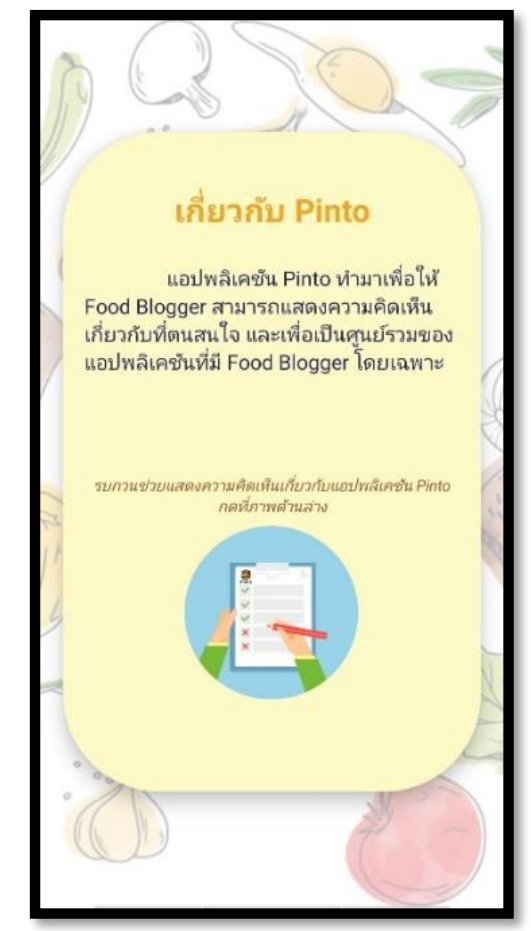

Figure 2: Main Page of Pinto Application

User account page showed details of the user account, including username, profile, picture, button for saving edits, number of posts, number of posts enthusiasts and other users who visited. Log in page for users was illustrated in figure 3. An example of user profile was shown in figure 4. 


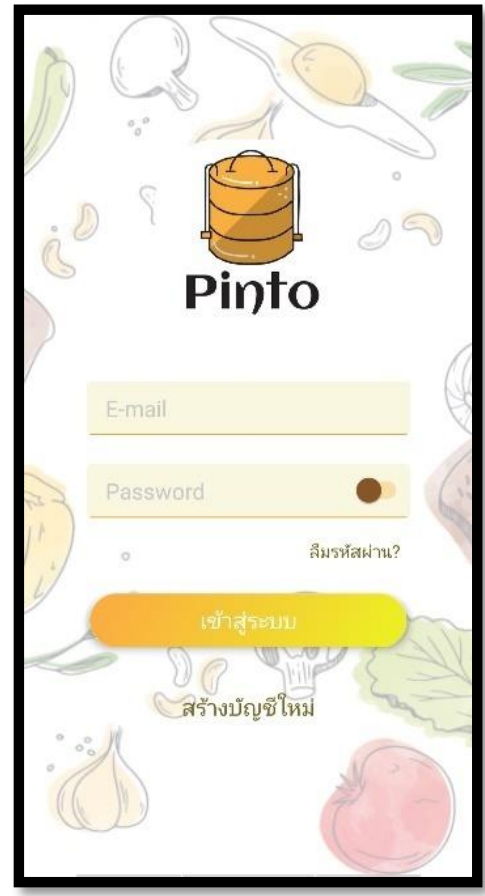

Figure 3: Log in Page for Users

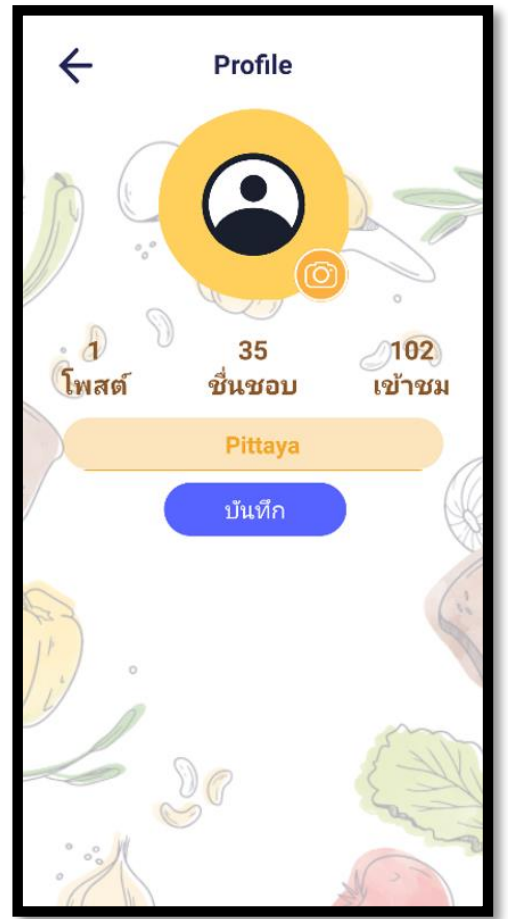

Figure 4: An Example of User Profile

The application provided food details information, such as food menus, ingredients, cooking process, etc. in terms of texts, pictures, and videos. Food information was classified in terms of food types, nature of food culture by countries, and popular food ranking. An upload page for food detail information and a post of noodle menu was shown in figure 5 . 


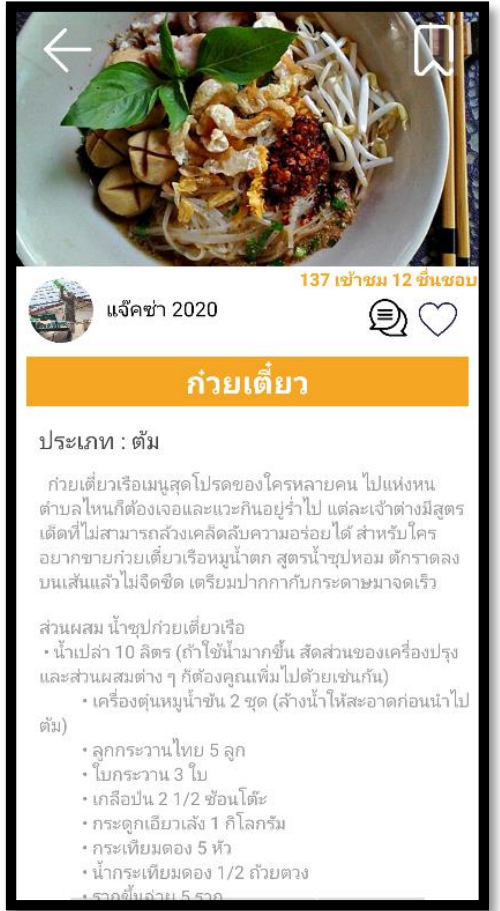

\section{Figure 5: Detail Information of Noodle Menu}

The application focused on colorful, beautiful, pleasant to use, which was appropriate for those who like to present food and let others know about restaurants and food in various restaurants. Comment page showed details about user comments with comments about posts which was illustrated in figure 6 and the top hits food menu page was shown in figure 7.

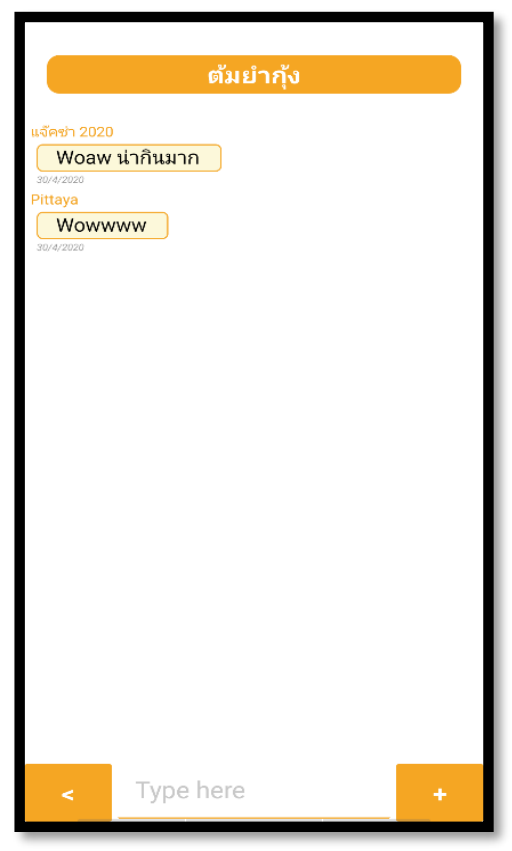

Figure 6: Comment Posting Page 


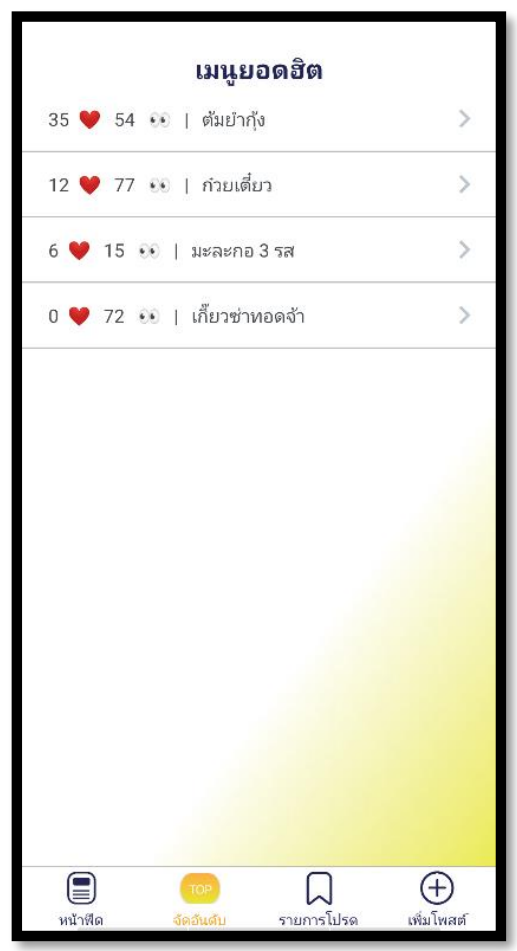

Figure 7: Top Hits Food Menu Page

\section{Discussion}

The useful of smartphone application for food bloggers were as follows: 1) it was easy use and cost savings, 2) it was an effective media for presenting opinions and author's feelings about various matters in order to propose to the public, 3) it can be a media for advertising, public relations, news, and movement of food business organizations, 4) it was a source of new food knowledge which was accurate and clear from that person, because blog writers tend to write about topics that they were good at, like, and have specific knowledge, especially for deep knowledge about food. Therefore, blog readers can discover new knowledge faster, 5) information was published up to date with current world events because the news and knowledge come from many food bloggers, 6) blog owner was free to offer anything that did not interfere with anyone else that does not violate the rules of blog service provider which is not illegal and morally pretty good traditions, 7) food bloggers had opportunity to hear freely exchange opinions, accept, not read, answer or delete. It depended on the discretion of the blog owner, 8) blog developers can create customized blog to their own style, 9) visitors can meet new friends and be able to network a community relationship between bloggers and visitors who have ideas, interests, feelings together, and 10) relevant information was recorded in storage of the organization's information.

However, food bloggers have to be careful about blog writing because they were free to present information without first reviewing, such as inappropriate topics. The owner of food blog must have rules for themselves or use individual ethics, rationality, caution, and be careful when for various message postings. Moreover, some contents on the food blog, which were not the research or thesis that according to the academic principles or the law, may be less reliable. If 


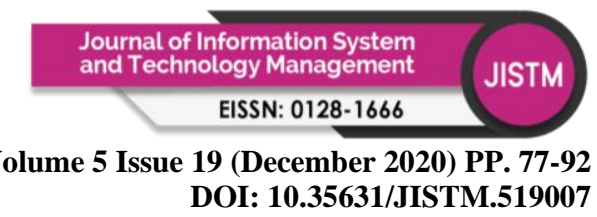

any mistakes occur, those who use the information for reference may experience problems. Those who do not wish may come to open a blog and harass. People with different opinions join in the same community for expression of unreasonable conflicts, create unity, and quarrel.

\section{Conclusion}

The developed smartphone application for food bloggers provided a social media channel. Pinto application composed of main page, user log in page, user profile page, food menu page, comment posting page, and top hits menu page. Users can register and log in through the application in order to submit their work by posting a message, pictures, and details about food information which they want to offer. Bloggers can edit posts which made by themselves easily. Visitors can follow food bloggers which they are interested in. They can post their comment and popular food will be ranked and illustrated at top hits food menu page. This study can be applied as a guidance of smartphone application development for bloggers in various business lines such as sports, costumes, and home decoration which they have to design and develop their specific blogs appropriately which it will help to increase competitiveness for sustainable business in the digital world.

\section{Suggestions}

The suggestions from the researcher were as follows: 1) the food blog owner should provide more foreign languages, such as English, Chinese, Japanese for users in order to promote Thai food tourism, 2) some famous food bloggers should be invited to write some interesting content in order to promote application marketing, 3) interesting cooking lesson should be provided to visitors, 4) food contents must be active regularly, 5) the application sponsors must be arranged as well, and 6) food block owner have to set good rules and regulations for food blockers and visitors clearly.

\section{Acknowledgement}

Financial assistance for this article publication was provided by a scholarship from Suan Sunandha Rajabhat University, Bangkok, Thailand.

\section{References}

Brandinside. (2016). Analyze the internet usage of Thai people 2016: Things that various brands must know. Retrieved February 8, 2020, from http//www.brandinside.asia/survey-internet-thailand-user-2559/

Bunyaporn, W. (2017). Review of restaurants via social media and the decision to choose restaurants for eating out of consumers in Bangkok. Retrieved February 8, 2020, from http://dspace.bu.ac.th/bitstream/123456789/2544/1/bunyaporn_vuti.pdf?fbclid=IwAR 25oUmsIuGPt5A3xrwYO30yAFZG8pXuShyiYMgWCyzbIAj0K_b55UMnSdY

Chatura, R., Harvir, B., \& Gordon, M. (2008). Web Site Satisfaction and Purchase Intentions: Impact of Personality Characteristics during Initial Web Site Visit. Journal of Service and Practice, 18(4), 329-348.

Designil. (2019). Concept and theory of application analysis and design. Retrieved February 8, 2020, from https://www.designil.com/7-rules-beautiful-ui-design.html

Isarawalee, N. (2561). Decision to use LINE MAN application services in Bangkok. Retrieved February $\quad 8, \quad 2020, \quad$ from http://dspace.bu.ac.th/bitstream/123456789/3081/1/isarawalee_neam.pdf

Kannika, H. (2013). Mobile application for national park tourism in Thailand. Received February 8, 2020, from http://projectrbru.weebly.com/uploads/5/0/7/2/5072410 
Kannikar, H. (2019). Food blogger. Retrieved February 8, 2020, from https://amarinacademy.com//5714design-idea/food-blogger/

Manoch, S. (2019). Thunkable. Retrieved February 8, 2020, from https://www.scimath.org/article-technology/item/9099-thunkable

Mowen, J. C., \& Michael, M. (1998). Consumer Behavior (5th ed.). Upper Saddle River, New Jersey: Prentice-Hall.

Nattha, Ch. (2010). Public Relations Strategy under the Trend of Social Network. Executive Journal. 173-183.

Online Seminar. (2014). Social media and teaching. Retrieved February 8, 2020, from http://smforedu.blogspot.com/2014/02/blog-post.html

Padthama, T. (2007). Local food consumption behavior of consumers in Phang Nga municipality area, Phang Nga province. Retrieved February 8, 2020, from http://rcfcd.com/wp-content/uploads/2014/03/9

Panthita, O., \& Tranakjit, Y. (2017). Exposure and consumer behavior on using Wongnai application. Proceedings of the 12th Graduate Research Conference, Pathum Thani, 538-547.

Pavinee, K. (2011). Principles of Marketing. Bangkok: Top

Phichit, W. (2011).Concepts and theories related to social media. Retrieved February 8, 2020, from http://library.senate.go.th/document/Ext9302/9302569_0004.PDF

Purim, Ch. (2016). Development of restaurant search system using Android system via GPS. Retrieved February 8, 2020, from http://itmjournal.rum.ac.th/journal/super20170109132952.pdf

Sahassa, I. (2008). Rich with blogger.com. Bangkok: Tarad Dot Com.

Schiffman, L. G., \& Leslie, L. K. (1994). Consumer Behavior (5th ed.). Englewood Cliffs, New Jersey: Prentice Hall.

Suchada, P. (2011). Trend in Using Mobile Applications. Executive Journal, 31(4), 110-115.

Tarika, P. (2011). Factors Affecting the People's Use of Smartphone Applications in Bangkok. Bangkok: Ramkhamhaeng University.

Thongchai, S., Sutha, P., \& Shinoros, T. (2020). Guideline for the use of mobile applications for tourism business in Bangkok. Proceedings of the 11th International Academic Conference "Global Goals, Local Actions: Looking Back and Moving Forward 2020", Bangkok, 32-37.

Westbrook, R. A., \& Oliver, R. L. (1981). Developing Better Measures of Consumer Satisfaction: Some Preliminary Results. Advances in Consumer Research. 8, 94-99.

Wolman, B. B. (1973). Dictionary of Behavioral Science. Van Nostrand: Reingeld Company. Wut, S. (2012). Consumer Behavior. Bangkok: G. P. Cyberprint.

Yamane, T. (1967). Statistics: An Introductory Analysis (2nd ed.). New York: Harper and Row. 